\title{
Fenômenos econômicos e critério metodológico de sua investigação
}

\author{
L. Nogueira de Paula \\ (Professor Catedrático da Universidade \\ do Brasil)
}

1. A simples observação dos fatos sociais revela-nos que entre todos os fenômenos de ordem econômica existem relações de mútua dependência, isto é, que a intensidade de cada um influe sobre a intensidade de todos os outros e deles simultaneamente depende.

Fenômenos de mútua dependência são, pois, aqueles em que a intensidade de cada fato influe sobre a intensidade de todos os outros e deles sofre, ao mesmo tempo, a influência.

A mútua dependência pode ser limitada ou geral.

A mútua dependência é dita limitada quando traduz relações recíprocas de causa a efeito, e dita geral quando exprime subordinação simultânea entre todos os elementos do mesmo fenômeno.

A própria divisão do trabalho nada mais é do que um dos aspetos dessa mútua dependência. Com efeito, observa Pareto: "Cada homem é um centro de influências econômicas que se exercem sobre uma infinidade de outros homens e um centro de recepção de influências econômicas que se exercem sobre êle" (1).

2. A observação nos mostra igualmente que os fenômenos econômicos não se despertam com a mesma intensi- 
dade, nem se propagam, no meio social, com a mesma velocidade de repercussão.

Assim por exemplo: "A taxa do câmbio e o nivel dos preços são duas ficções estatísticas, pelas quais se podem apreciar com vantagem as condições gerais do estado monetário do organismo econômico.

Sofrendo este organismo depressões que ocasionem um estado patológico, imediatamente aquelas ficções acusarão a anormalidade despertada, com prioridade de reflexo na taxa cambial, - valor signalético de maior sensibilidade e posteriormente no nível dos preços, cujas variações são mais lentas" (2).

Referindo-se ás manifestações dessa natureza, afirma o professor Jorge Kafuri que "tais reações se distinguem, substancialmente, pela intensidade com que se despertam e pela velocidade com que se propagam, havendo as que se manifestam com fulminante rapidez, enquanto outras levam meses e por vezes anos e decênios para se despertar" (3).

$\mathrm{Na}$ investigação dos fenômenos econômicos cumpre, portanto, levar em consideração não somente a sua intensidade como tambem a sua velocidade de repercussão sobre os outros fenômenos.

Repercussão de um fenômeno econômico é o efeito produzido no organismo econômico pelo fenômeno considerado.

Assim, por exemplo, comumente se diz que as crises monetárias têm grande repercussão sobre 0 comércio interior.

Intensidade de um fenômeno econômico é a grandeza do efeito por êle produzido.

A superprodução de um produto, por exemplo, tem grande efeito sobre o seu preço de venda.

Velocidade de repercussão é o acréscimo da repercussão na unidade de tempo.

A quebra do padrão monetário, por exemplo, repercute em geral com grande velocidade sobre a taxa cambial. 
3. Os fenômenos de fraca intensidade e de baixa velocidade de repercussão são suscetiveis de apreciação e análise pelo raciocinio formal, por isso que em primeira aproximação podem ser considerados de mútua dependência limitada, exprimindo relações reciprocas de causa a efeito; ao passo que os fenômenos de grande intensidade e de alta velocidade de repercussão só podem ser estudados e interpretados por um raciocínio de tipo superior, pois, sendo fenômenos de mútua dependência geral, traduzem subordinação simultânea entre todos os seus elementos, o que não está mais ao alcance da linguagem ordinária.

Efetivamente, nos fenômenos do primeiro gênero, isto é, nos fenômenos de fraca intensidade ou de baixa velocidade de repercussão, sendo linear a interdependência nos periodos de curta duração, isto é, representada por uma equação do $10^{\circ}$ gráu, são permitidas ao racionínio formal a sua apreciação e a sua análise, porque as variações da causa são proporcionais ás variações do efeito.

No caso, porém, d'os fenômenos do segundo gênero, isto é, dos fenômenos de grande intensidade ou de alta velocidade de repercussão, a mútua dependência não sendo mais linear, isto é, não sendo mais representada por uma equação do $10^{\circ}$ gráu, impede á linguagem ordinária o seu estudo $e$ interpretação, porque as variações dos antecedentes não são mais proporcionais ás variações dos consequentes.

PARETo esclarece muito bem esse assunto com as seguintes palavras: "Examinemos as dificuldades encontradas quando queremos raciocinar sobre o fenômeno econômico com a linguagem ordinária.

Comecemos por questões muito simples.

Carlos dá 4 peras a Pedro, Luís dả-lhe 3, Antônio 5 . Quantas peras recebeu Pedro? A resposta é muito fácil. Uma simples adição indica que Pedro recebeu 12 peras. Em geral todo problema em que ha uma incógnita igual a certa combinação (comumente uma soma) de quantidades conhecidas, pode ser resolvido mais ou menos facilmente 
por meio da linguagem ordinária. Quasi sempre a economia não matemática ensáia dar aos problemas econômicos fórmas análogas, para poder resolvê-los.

Compliquemos um pouco mais a questão. Pedro tem um número desconhecido de peras e tambem úm número desconhecido de maçãs. Ha duas condições: - 1. ${ }^{\mathrm{a}}$, o número de peras é igual ao dobro do número de maçãs mais uma; 2.a, o número das peras mais o número das maçãs é igual a 10. Este problema não póde ser resolvido, facilmente, pela linguagem ordinária. Num instante, porém, a álgebra nos ensina que o número de peras é igual a 7 e 0 de maçãs igual a 3 .

Eis duas incógnitas e duas condições bem simples... Mas suponhamos, entretanto, que temos uma centena de incógnitas e tambem uma centena de condições. Eis ai um problema absolutamente insoluvel sem o auxílio poderoso da matemática.

O problema econômico é, ainda, bem mais complicado. Nós temos de considerar milhares e milhares de mercadorias produzidas e permutadas por numerosos individuos. Essas permutas são determinadas pelas equações da Economia Pura e não se vê como seria possível fazer de outra fórma. Possuimos, então, um sistema de condições, ou, melhor, um sistema de equações, dando-nos a imagem aproximada do fenômeno econômico, da mesma fórma péla qual uma esfera nos dá a imagem da terra" (4).

4. Tudo isso revela a dificuldade e, algumas vezes mesmo, a impossibilidade que apresenta ao analista o estabelecimento das relações de mútua dependência geral entre os fenômenos econômicos quando se leva em consideração, simultaneamente e de modo geral, a sua intensidade e a sua velocidade de repercussão.

Resulta daí que, na impossibilidade de realizar-se a condição acima, - estabelecimento das relações de dependência Cos fenômenos entre si, - o economista é forçosa- 
mente obrigado a renunciar, a priori, á noção de certeza absoluta para substitui-la pela noção de probabilidade.

"Por todas estas razões -- escreve Porncaré - nenhuma lei particular poderá jamais deixar de ser apenas aproximada e provavel. Os sábios nunca desconheceram esta verdade: simplesmente creem, com ou sem razão, que toda lei poderá ser substituida por outra mais aproximada e mais provavel, que esta lei nova será, por sua vez, apenas provisória, mas que o mesmo movimento poderá continuar indefinidamente, de modo que a ciência, progredindo, possuirá leis cada vez mais provaveis; que a aproximação acabará por diferir tão pouco quanto se queira da exatidão, e a probabilidade, da certeza" (5).

Esse método das aproximações sucessivas está, aliás, de acôrdo com a própria índole da investigação econômica, indefinidamente progressiva.

A esse respeito observa CaIRnes, com muita propriedade: - "A ciência econômica longe de ter completado sua obra como ás vezes se supõe e que, assim, obsoleta para as realizações práticas, seja objeto de simples curiosidade histórica, pertence, pelo contrário, á classe das ciências cujo trabalho jamais poderá ser completado, jamais, pelo menos, enquanto os homens continuarem a progredir; pois a parte mais importante dos dados em que fundamenta seus raciocínios é o carater humano e as instituições humanas e, por conseguinte, qualquer coisa que afete esse carater ou essas instituições deve criar novos problemas para a ciência econômica" (6).

5. Do exposto se evidencia que a extrema complexidade dos fenômenos econômicos, aliada á impossibilidade do conhecimento perfeito de todas as causas determinantes de um mesmo fato, obriga o analista a estabelecer, em primeiro logar, as relações de causalidade. Em seguida, com as noções anteriormente adquiridas e graças ao aperfeiçoamento dos processos de investigação, ele procura determinar então 
as ligações de interdependência que subordinam entre si os diversos elementos da atividade econômica.

6. Essas observações influirão, por certo, decisivamente, na solução dos problemas econômicos e no gráu de perfeição de que os mesmos são suscetíveis. A tal respeito são, ainda, de Carrnes as seguintes e oportunas palavras: "Uma lei econômica exprime, não a ordem em que os fenômenos se apresentam, mas a tendência a que êles obedecem; quando ela se aplicar a acontecimentos exteriores, é verdadeira sómente na ausência de causas perturbadoras; por conseguinte representa uma verdade hipotética e não positiva; sendo deduzida por consequência necessária de certos principios mentais e físicos, ela não pode ser estabelecida sem que se admita, em primeiro logar, a existência das hipóteses estabelecidas e sem que se demonstre que, por necessidade lógica, elas acarretam a tendência suposta; e só pode ser refutada se se provar que os principios não existem, ou que o raciocínio é vicioso. Sob esse ponto de vista, procuramos demonstrar que o carater de uma lei econômica é estritamente análogo ao das leis da natureza física que se obteem ou que podem ser obtidas por dedução dos princípios últimos das ciências a que pertencem. Eis até onde vai a analogia em Economia Política com as leis das ciências físicas mais adiantadas, tal como as comprendemos"

Mais adiante acrescenta ainda: "Nos dois ramos do conhecimento, uma lei natural exprime, da mesma fórma, uma tendência que exerce influência constante sobre os fenômenos; nas ciências físicas, porém, a descoberta de uma lei natural só é considerada completa quando, além da tendência geral, encontra uma expressão numérica exata para o gráu de fôrça segundo o qual age a tendência em questão"

E finaliza com as seguintes conclusões: - "Eis, entretanto, um gráu de perfeição que nos parece impossivel ver atingido pela Economia Política, assim como pelo direito, pela filologia ou por qualquer outro ramo do conhecimento 
que fundamente suas premissas nos principios da natureza humana; pois, ainda que o carater geral desses princípios possa ser estabelecido, ou mesmo que, se estabelecidos com precisão suficiente, esses princípios possam constituir a base de importantes deduções, não admitem eles, entretanto, pela natureza do fenômeno, nem pêso nem medida como os elementos e as fôrças do mundo material; não são, pois, suscetíveis de expressão aritmética; e resulta daí que, especulando sobre os resultados que dependem da fôrça positiva ou relativa desses princípios, não se pode chegar nem a rigorosa precisão, nem a exatidão numérica" (7).

7. As leis econômicas sendo, pois, tendenciais só podem exprimir os grandes sentidos por que se inclinam os fenômenos da vida coletiva e não fornecer expressões quantitativas exatas como desejam ou julgam muitos, sem que por isso coisa alguma percam de seu valor científico.

“Tal é, pois, o carater de uma lei econômica, análogo sobre todos os pontos de vista ás leis da natureza física que se obteem por um processo semelhante de raciocínio dedutivo, com a diferença importante de que a lei econômica não admite determinação quantitativa. Isso posto, estamos em condições de compreender até onde as leis econômicas podem servir para a explicação dos fenômenos econômicos.

A explicação de um fenômeno ou a solução de um problema (sendo expressões equivalentes) consiste em aplicar princípios conhecidos ou reconhecidos ao fato que se tem de resolver ou de explicar. A marcha rápida de um planeta no espaço, por exemplo, é explicada quando se mostra que esta velocidade é o resultado de princípios dinâmicos conhecidos" (8).

Outro exemplo elucidativo é o citado pelo grande pensador inglês: - "Da mesma maneira, o fenômeno econômico da renda, como se diz, é explicado quando se mostra que ele é a consequência necessária do jogo dos interêsses hunıanos decorrentes de um objeto que tem as propriedades físicas particulares encontradas na terra. Nesse caso, igual- 
mente, se admitimos que os sêres humanos, em sua fórma de tratar a terra, agem tendo em vista seu próprio interêsse, que os melhores terrenos relativamente á fertilidade e situação não são ilimitados na oferta e, além disso, que o rendimento a ser obtido de uma superfície limitada não é tambem ilimitado, porém diminue proporcionalmente á despesa, á medida que aumenta a quantidade produzida, vemess ou, melhor, raciocinando sobre esses fatos, pudenos ver que o fenômeno da renda deve, necessariamente, manifestar-se no progresso da sociedade e, ainda, que ela subirá ou baixará segundo as causas que, como vimos, a afetam na realidade. Sob esse ponto de vista, pois, a solução do problema econômico é estritamente análoga a do problema físico; em cada caso, o processo consiste em remontar do fato a explicar até seu fundamento nos princípios últimos da ciência; se fôr um fato físico, ás leis últimas da natureza física; se fôr um fato econômico, aos axiomas últimos da Economia Política, isto é, aos princípios mentais e físicos de que derivam suas doutrinas. Enquanto essa conexidade não fôr claramente estabelecida, não se pode pretender haver explicado nenhum fenômeno físico ou econômico.

A solução de um problema pode ser encarada como perfeita quando se mostra que os princípios aos quais ele se adapta existem e conduzem por consequência necessária ao fato preciso que constitue o problema a resolver. Supondo nosso raciocínio correto, é evidente que a imperfeição pode ainda provir tanto da indeterminação de nosso conhecimento das leis que atuam para produzir o fenômeno quanto da ignorância das circunstâncias precisas em que elas são postas em ação.

Com exceção talvez da Astronomia, não ha ciência que tenha atingido á perfeição absoluta nesses dois pontos de vista. A maioria das ciências físicas adiantadas satisfaz, entretanto, a primeira condição, ainda que geralmente se ressinta de completa exatidão quanto á última" (9). 
8. “Tanto na Economia Política quanto na Física, observa ainda CAIRnes, - antes de se proceder á explicação do fenômeno, é conveniente certificar-se de sua existência. Estabelecido esse ponto preliminar, o problema deve ser resolvido não por frases vagas e suposições gerais, mas pela redução do fenômeno aos princípios últimos da ciência a que ele pertence; no caso da Economia Política são certas propensões conhecidas da natureza humana e certos fatos estabelecidos do mundo exterior" (10).

9. Na multidão dos fenômenos e na infinita variedade com que os fatos se apresentam, cumpre ainda ao economista não perder de vista as judiciosas ponderações de Murray, em suas sábias Lições de Economia Política:

"Para poder estudar eficazmente os fenômenos econômicos que a observação nos apresenta como extremamente complexos, quatro necessidades particulares se impõem:

1. ${ }^{a}$ - limitar o mais possivel e determinar rigorosamente o campo de nossas pesquisas, á vista da diversidade das fórmas da vida;

2.a) - proceder por aproximações sucessivas á descoberta das uniformidades que os mesmos fenômenos apresentam;

3. $\left.{ }^{a}\right)$ - recorrer á matemática, quando as relações forem tão complicadas que o raciocínio ordinário não possa seguir nem compreender;

4. ${ }^{\mathrm{a}}$ ) - ocupar-se unicamente do fato real, isto é, aceitar sómente o fruto da observação dos fatos" (11).

10. Vemos, portanto, que é a própria natureza dos fatos sociais que vai ditar ao analista o tipo de raciocínio e o recurso metodológico de que, em cada caso especial, deve lançar mão para a interpretação lógica, a investigação científica e a exposição didática dos fenômenos econômicos. 


\section{B I B L I O G R A F I A}

1 - Vilfredo Pareto - "Introduction" in "Théorie Mathématique de l'Échange", de Antônio Osório - Paris, 1913. M. Giard \& E. Brière. 1 vol. in-8. ${ }^{\circ}$ de 396 pgs. - pág. XII.

2 - L. Nogueira de Paula - "Normas de Política Monetária" Rio, 1933. Irmãos Pongetti. 1 vol. in-8. ${ }^{\circ}$ de 300 pgs. pág. 206.

3 - J. Felipe Kafuri - "Notas de Economia Matemática" in "Lições de Economia Politica", de Carlos Porto Carreiro - 3.a edição - Rio, 1935. F. Briguiet \& Cia. 1 vol. in $8 .^{\circ}$ de 604 pgs. - pág. 591 .

4 - Vilfredo Pareto - "Artigo in "Giornale degli Economisti" Setembro de 1901, citado por G. H. Bousquet in Vilfredo Pareto - "Sa vie et son oeuvre" - Paris, 1928, Payot. 1 vol. in-8. ${ }^{\circ}$ de 227 pgs. - págs. 66 e 67.

5 - Henry Poincaré — "La Valeur de la Science" - Paris, 1932. Flammarion. 1 vol. in-16 de 278 pgs. - pág. 251.

6 - John Elliot Cairnes - "Le Caractére et la Méthode Logique de l'Économie Politique" - Tradução francesa de G. Valran. - Paris, 1902. V. Giard \& E. Brière. 1 vol. in-8..$^{\circ}$ de 272 pgs. - pág. 34 .

7 - John Elliot Cairnes - op. cit. - pág. 132.

8 - John Elliot Cairnes - op. cit. - pág. 142.

9 - John Elliot Cairnes - op. cit. - pág. 143.

10 - John Elliot Cairnes - op. cit. - pág. 157.

11 - R. A. Murray - "Leçons de Économie Politique" - Tradução francesa de Pierre Boven. - Paris, 1920. Payot. 1 vol. in-16 de 502 pgs. - pág. 9 . 